\title{
Correlates of intention to abstain from sex among HIV positive adolescents in Botswana
}

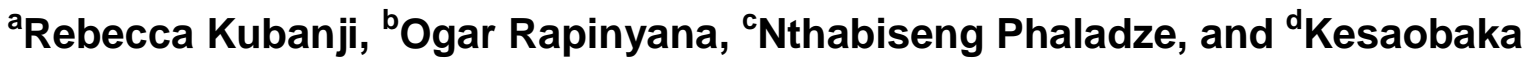 \\ Molebatsi
}

aDepartment of Population Studies, University of Botswana, Phakalane, Gaborone, Botswana,

Rebecca.Kubanji@mopipi.ub.bw

bSchool of Nursing, University of Botswana, Gaborone, Botswana

'School of Nursing, University of Botswana, Gaborone, Botswana

${ }^{\mathrm{d} D e p a r t m e n t}$ of Statistics, University of Botswana, Gaborone, Botswana

\begin{abstract}
The study assesses correlates of abstinence intention among HIV positive adolescents aged 15-19 years to identify salient behavioural, normative and control beliefs relevant to sexual risky behaviour using the theory of reasoned action and planned behaviour. A cross sectional survey of 98 HIV positive adolescents aged I5-19 years was conducted at a Children's center and from the infectious disease care clinics in Mochudi. Among 98 respondents, $56 \%$ were females (mean age 15.80, $\mathrm{SE}=0.2 \mathrm{I}$ ) and $44 \%$ were males (mean age 15.73, $\mathrm{SE}=0.187$ ). Abstinence behavioural beliefs $(p<0.000 \mathrm{I})$, abstinence prevention beliefs $(p<0.000 \mathrm{I})$ and abstinence normative beliefs $(p=0.025)$ were significantly associated with intention to abstain from sex. Investing in interventions that enhance behavioural and prevention beliefs and promote intention to abstain would reduce the risk of reinfection, STDs and delay sexual debut. HIV interventions targeting adolescents would help prevent new infections.
\end{abstract}

Key words: Abstinence, Adolescent, HIV, Botswana, theory of reasoned action

\section{Introduction}

Sub-Saharan African bears the biggest global burden of HIV and AIDS, and it is mostly heterosexually transmitted. Sexual risk among adolescents is one of the major public health concerns. Additionally, adolescents living with HIV and AIDS (ALWHA) have become the focus of much research and policy attention. The reason is that if HIV re- infection is not prevented among these adolescents, there is bound to be a cycle of HIV infection and re-infection, which will in turn be costly to the public health sector.

Empirical evidence reveals that prevention with a positive approach that integrates preventive messages in HIV care and treatment is one of the new strategies that can curb new HIV infections. As such, the extent

to which HIV infected individuals practice risky sexual behaviours is relevant in designing population appropriate intervention(Mhalu, 20/3). Research further documents that due to social change, premarital sexual behaviour has become common over time. This is mainly due to non-communication between adolescents and parents on family life issues such as sex, pregnancy and contraception, this is made worse by cultural beliefs, and religion which insists on chastity. These doctrines have become a dominant factor in adolescent sexual and reproductive health matters(Ogunjuyigbe, 2014). Abstinence as a prevention strategy faces a number of challenges in the wake of a vast change in subjective norms, normative beliefs, psychosocial and economic factors influencing adolescents (Kabiru, 2007). The authors further highlight eight principles underlying abstinence education as follows; a)abstinence yields social, psychological and 
health benefits; b) it is the expected standard for children in school; c) it is the only 100\% effective way to prevent pregnancies outside marriages, STIs and other risks arising from sexual intercourse; d) sexual activity should occur in a mutually monogamous relationship within marriage; e) negative psychosocial and physical effects are likely to occur as a result of sexual intercourse outside marriage; f having children outside marriage is likely to have negative effects for the child, parents, and society; g) there is a need for the youth to be taught sexual refusal skills and to learn how drug use, including alcohol use, impairs judgement about sexual activity; and h) young people should be self-reliant before being sexually active.

Research reveals that the major predictors that are significantly associated with sexual abstinence include being a female, not having a boyfriend or girlfriend, not using alcohol and having a positive attitude towards abstinence. Additionally, perceived self-efficacy to refuse sex and negative perception of peers who engage in sexual behaviour are identified as additional predictors of sexual abstinence(Oladepo, 20II). In the same study, a small proportion of male respondents $(79 \%)$ were abstinent, when compared with their female counterparts (98\%).

As more perinatally infected adolescents survive on antiretroviral therapy(ART), current research focus on HIV care is more towards improving the quality of life of adolescent(Mbalinda, 20I5b). The authors advocate for the need to design and integrate age appropriate and culturally applicable screening and management of mental health in sexual reproductive health $(\mathrm{SRH})$ services among adolescents aged 10 - 19 years in Uganda.

In a study on misconceptions and fears about sex among 15 - 19 year old adolescents verticallyinfected with HIV in Tanzania,(Busza, 2013) corroborate with (Mbalinda, 20I5b) by reiterating that adolescents were likely to experience significant unmet need as they initiated sexual relationships. This gap is due to adolescents experiencing restricted access to accurate information, appropriate guidance and comprehensive reproductive health services. Programmes could help to reduce this gap by facilitating open communication about sexuality between adolescents and their caregivers, providers and HIV - positive peers.

According to the Botswana AIDS Impact Survey IV, HIV prevalence among those aged $15-19$ is estimated at 5\%(3.6\% males and $6.2 \%$ females) (Statistics Botswana, 2013). The majority of the children in this age group got infected through vertical transmission. Between 2008 and 2013, it is evident that adolescents in Botswana engaged in risky sexual behaviours. Low rate of condom use with casual partners among $15-19$ years males as compared to their female counterparts is reported(NACA, 2014).

In 201 I, 2000 adolescents were enrolled in the government antiretroviral (ARV) programme, and in 2013 , the figure rose to $4833,56 \%$ females and $44 \%$ males. As more children survive and live longer due to ARVs, the adolescence age stage needs to be catered for as these teenagers are in transition, emotionally, psychologically and physically. Theory based abstinence only interventions have an important role in preventing adolescent sexual risky behaviour and reinfections for adolescents living with HIV and AIDS regardless of their limitations. Based on the reasoned action approach, this study aims at investigating the predictors of abstinence among adolescents living with HIV and AIDS. There is dearth of literature on abstinence interventions in Botswana and very few studies in the region. We believe that abstinence interventions targeting adolescents living with HIV would promote positive behavioural and prevention beliefs to reduce HIV transmission, STDs, reinfection and delay sexual debut. Therefore, this study assesses correlates of abstinence intention among HIV positive adolescents aged I5-19 years to identify salient behavioural, normative and control beliefs relevant to sexual risky behaviour using the theory of reasoned action and planned behaviour.

\section{Literature Review}

Abstinence only interventions may be desirable in curbing early infections with HIV; however they may not be an effective approach on their own. Literature emphasises on a mix of approaches including limiting sexual partners, reducing multiple sexual partners and use of condoms. The limitation of abstinence only interventions is that they have an unintended effect of reducing condom use, which predisposes adolescents to unprotected sexual activity (lemmott, 20I0). Inadequate knowledge about condoms and contraception is associated with sexual abstinence among both males and females. Thus empowering adolescents with adequate information and skill pertaining to condom use will help to prevent STIs, unintended pregnancy and HIV and AIDS. Furthermore, it is revealed that peer education is effective in promoting social norms, puts emphasis on decision making skills and value on education.

Sexual risk behaviours is reported among perinatally infected adolescents including; reported symptoms of STIs among $16.2 \%$ of adolescents; 
sexual activity among more than one third (34.1\%) versus $65.9 \%$ who were abstinent; $76.5 \%$ of condom use inconsistency; $49.3 \%$ of ever been pregnant or made someone pregnant; non disclosure and non- awareness of partners' HIV status (56.3\%). This calls for coordinated risk reduction interventions and efforts that can reduce risky sexual behaviours among adolescents(Mbalinda, 20I5a).

The Mississippi state has invested millions of federal funds into abstinence- only - until marriage programs for nearly a decade without success, indicating the failure of such programs(Culp- Ressler, 2014). It has been proved that the state has the second highest rate of teenage pregnancies, second highest rates of gonorrhoea and chlamydia infections, and the seventh highest rate of HIV infections in USA. The author thus recommends that instead of concentrating on abstinence - only programs as the solution for decreasing sexual activity, a comprehensive sex education is an effective tool for accomplishing such an objective.

Community collaboration can also harness these combinations of approaches(Lacson, 1997). (Kirby, 20II) also emphasise the need for intentions to be augmented by the skills to implement those intentions and a conducive environment to encourage such efforts. Nonetheless,(Zhang, 2015), acknowledge that consistent with the theory of reasoned action, abstinence only interventions worked through behavioural beliefs about the positive consequences of abstinence rather than the negative consequences of sex. Such beliefs in turn reduced intention to have sex. Furthermore, the authors argue that adolescents' normative beliefs about sex were a significant predictor of sexual involvement. This implies that there is need for interventions that focus on adolescents and their parents and their close friends. Such may change beliefs in expected approval, which may in turn delay sexual initiation. As such the authors reiterate that abstinence only interventions should focus on the psychological mechanisms underlying behaviour change. This is in the context of African American adolescents.

Similarly in a study of Korean college students, the authors compared male and females students. Female students are more consecutive about premarital sexual attitudes, and were more confident in relation to non - engagement in sex before marriage. Conservative parental premarital sexual norms influenced these students, with fathers' norms highly influencing females, while mothers' highly influenced the males (Cha, 2007) . Parents have been in many instances shown to be among the most significant influences on adolescents' sexual risk related attitudes, intentions, and behaviours. Thus in designing intervention to reduce adolescent sexual risk behaviours, there is need to conceptualise beyond the individual level. The need to design family - based prevention programs is therefore in order (Hutchinson, 2007). In a Jamaican study, majority of mothers were uncomfortable to share sexual matters with their daughters. They believe that such discussions may trigger their daughters to initiate sexual activity, thus indicating poor role modelling among these parents .In contrast, a few mothers depict positive mother - daughter relationship quality(Hutchinson, 20I2).

Abstinence remains the best strategy to avoid HIV risk behaviours, especially for HIV positive adolescents. In this regard, there is need for adolescents to learn, synthesise and apply the abstinence strategy in their life experiences. This will in turn avert infections, re-infections and pregnancy, among others. (Georges, 20I3). If sexual abstinence is practised among perinatally- infected adolescents to whom access to sexuality is somehow delayed, it negatively affects the sexual life of HIV - positive adolescents (Mergui, 20I I).

Gender differences exist in abstinence intention. In a study in Tanzania, among males, the strongest predictor to abstain till marriage was sharing a bedroom with a brother under age 18 and believing in girls' right to participate in sexual decision making. However for females, it was living with both parents and self- efficacy to refuse sex with someone in power (Njau, 2009). Intention to abstain is one of the safer sex behaviours that positively correlate with high self- efficacy than high self- esteem (Chilisa, 20I3). Given that behaviour change is Botswana's focus in its fight against HIV and AIDS, the findings of this study can better inform intervention measures used in reducing the spread of HIV and AIDS among adolescents.

A study among Swazi in- school youth aged between 15 and 19 years reflects that subjective norms are the strongest predictors for premarital sexual abstinence. This reflects the influence that parents have in enhancing effective promotion of sexual abstinence among Swazi youth. These findings are within the context of Swazi traditional norms that require that girls retain premarital virginity. Attitudes were fairly reliable predictors on intentions to abstain, while the least reliable predictors were perceived behavioural control (Sacolo, 20I3).

(Godswill, 20I4) identifies a conflict between cultural survival on adolescents and fear about their personal identities as powerful factors that motivate sexual and reproductive behaviour.The 
author alludes to many unmet reproductive needs for African adolescents, irrespective of a variety of reproductive health programs available. The challenges experienced by these $15-19$ year old adolescents in Northern Nigeria, include lack of courage to approach health care providers and parents with reproductive health issues. These adolescents need intervention programs that can tackle issues of empowerment, access to resources and improved information and services. In an Islamic context, health professionals are to target interventions regarding sexual issues including health beliefs and religious spiritual beliefs. The importance of using behaviour change theories and models for designing interventions aimed at reducing sexual activity and controlling premarital sex cannot be overemphasized(Ghaffari, 2016). Furthermore the authors reiterate the need for cultural appropriateness in interventions aimed at delaying sexual initiation and preventing sexual behaviours before marriage among adolescents and young adults.

The importance of the need to raise public awareness among parents and public health care workers about the need for a stable emotional environment for children while growing up is crucial(Kasbom, 2016). In this Swedish study, adolescents with no sexual experience by the age of 18 years of age seemed to live a more stable and cautious life than their more sexually experienced peers. These behaviours were characterised by fewer antisocial acts, less smoking and alcohol/ drug ingestion, less sexual desire and less experiences of sexual abuse.

(Leerlooijer, 2014) argue that perceived behavioural control was highly associated with abstinence intention, and there were no gender differences regarding such. Perceived supportive norms of peers are strongly associated with adolescents' motivation to abstain. In the same study, there was a positive attitude towards abstinence, with females generally motivated to abstain than males. This could however be explained by the larger proportions of females who were sexually inexperienced as compared to their male counterparts. Additionally abstinence motivation was more pronounced among younger females than older ones.

\section{Theoretical Framework}

The study utilises the Theory of Reasoned Action Approach (RAA) - (Fishbein, 20I0); (lemmott, 2012b), which is a combination of the theory of reasoned action (Aizen, 1980); (Fishbein, 1975) and the Theory of Planned Behaviour (Ajzen, 199|). It was developed in a process that involved integrated qualitative information from formative research with behaviour-change theory that was both culturally congruent and theory based. According to the RAA, intention is the main determinant of behaviour and attitude, subjective norm, and perceived behavioural control or self-efficacy regarding the behaviour that determines intention. The RAA also directs attention to the specific beliefs that underlie attitude, subjective norm, perceived behavioural control, and holds that these beliefs can be targeted by behaviour-change interventions (lemmott, 20/2a). For instance, attitudes toward behaviour are seen as reflecting behavioural beliefs about the consequences of performing the behaviour. The RAA provides a useful framework for an HIV/STI risk reduction intervention intended to build self-efficacy and foster positive attitudes toward safer sex, and delay sexual activity among ALWHA. (lemmott, 2010) purport that the ideal abstinence intervention would incorporate principles of efficacious HIV/STI risk reduction behavioural interventions. They further acknowledge that the intervention would draw from formative research on the population and behaviour change theory to address motivation and build skills to practice abstinence.

The debate on abstinence only interventions is ongoing; however most studies indicate that the abstinence approach has appeal because adolescents, particularly young adolescents, may lack the knowledge and judgment to make informed choices to protect themselves from pregnancy and sexually transmitted diseases (STDs) or to grapple with these adverse consequences of unprotected sexual intercourse.

The Reasoned Action Approach was used to determine the outcome and the predictor variables during development of the survey. The theory of reasoned action and planned behaviour was used to explore ALHWA's intention to abstain from sex. Based on the theory, intentions are predicted by attitudes and beliefs that influence one's intention to abstain.

The Reasoned Action Approach (RAA) has proved to be a useful framework for assessing correlates of safer sex behaviour in Uganda (Rijsdij, 20I2). The authors argue that comprehensive sex education directed towards Ugandan adolescents should address the socio-cognitive predictors as proven by the study. These include attitudes towards, social norms about and self- efficacy to delay sexual activity among those with and those without previous sexual experience, and social norms towards condom use among those with previous sexual experience. 
It is evident from research that adolescent research has become a point of focus and policy attention all over the world. It is revealed that it is important to avoid re-infection which in turn is costly to the public health sector. Unprotected sex and multiple partnerships are factors associated with transmitting HIV infection. Non communication between adolescents and parents on family issues such as sex, pregnancy and conception, has been identified as some of the issues that contribute to their lack of knowledge, skill and empowerment. Abstinence as a preventative strategy is facing a number of challenges as a result of changes in norms, normative beliefs, psychological and economic factors influencing adolescents.

\section{Ethical Considerations}

Ethical approval was obtained from the institutional review boards of the University of Botswana and University of Pennsylvania, and the Health Research Development Committee of the Botswana Ministry of Health; and ethical clearance and permissions were obtained from the management of the Childrens' centre and the Infectious Disease Care Clinics (IDCCs). A written consent was obtained from parents and guardians, while assent was sought from ALWHA.

Participants were recruited from the children's centre and the IDCCs through the assistance of the Adolescent Officer and the registered nurses working with adolescents and their parents and care givers. All adolescents in the study were aware of their HIV status and were accessing HIV care and management services. Participation in the study was voluntary. Confidentiality and privacy were ensured by entering data in a password protected computer and use of codes instead of real names.

\section{Data and Methods}

Data was obtained from a cross sectional quantitative survey of 98 adolescents living with HIV and AIDS (ALWHA) aged 15-19 years. They were recruited from a specialised child care centre in Gaborone and infectious disease care clinic in Mochudi managing HIV clientele between June 2009 and July 20 I0. This survey was informed by qualitative research (Phase I) that uncovered adolescents' beliefs, attitudes, values and motivations that underlie individual intentions to engage in and/not engage in sexual risky behaviours.

To identify participants for the survey, health care providers at the infectious disease care clinic (IDCC) and at the children's center assisted with the recruitment of participants (parents and ALWHA). A list of potential participants (ALWHA) was generated which included a list of phone numbers for their parents and guardians. Some parents and adolescents were told about the study by health care providers at the health facilities when they came to the health facilities for medical check-ups. The researchers would then collect the information from the health care providers and then call the parents/guardians of the adolescents and talk to them about the study, and if they wanted an appointment to talk about the study that would be scheduled, and consent for their children to participate would be sought. If the parent or caregiver consented then the researchers would get contact details of ALWHA from the parent/caregiver and contact the adolescent about the study and sought their assent. Thereafter an appointment to conduct interviews would be scheduled.

To be eligible, participants were aged 15 to 19 years of age, HIV positive; knew their status, assented and parents consented for data collection.

\section{Construction of Variables}

Construction of both dependent and independent variables involved taking the means of questions measured on a 5 point Likert scale ( $I=$ strongly disagree, $2=$ Agree, $3=$ Neutral, $4=$ Agree and 5= strongly agree). Cronbach's alpha for each theoretical construct were calculated to estimate the reliability of each scale, these statistics are presented in Table I. All the Cronbach's alphas are more than 0.60 hereby implying a greater reliability among both dependent and independent variables. A construct scoring a mean more than 2.5 , which is half of the maximum (5), will be deemed higher and lower if below. A score of 2.5 will mean an average has been obtained. It is important to note that partner reaction and socio cultural beliefs imply unwanted behaviours. For example, items " $i$ have been worried that if I talked about abstinence, my partner might ignore my request" and "if a guy abstains from sex, his penis will not erect anymore" should give us low scores for good behaviour. This is because lower scores were given for strongly disagreeing respondents. Therefore a low score is required for this construct if individuals portray good behaviour. 
Table I: Constructs and Cronbach's Alphas (Items were measured in a 5 point Likert scale), i.e. $\mathrm{I}=$ Strongly disagree, $\mathbf{2}=$ Agree, $3=$ Neutral, $4=$ Agree and $5=$ Strongly agree.

\begin{tabular}{ll}
\hline Construct $\quad$ Example Items & $\begin{array}{l}\text { Number Alpha } \\
\text { of items }\end{array}$
\end{tabular}

Abstinence Intention

I plan to abstain in the next 3 months

2

0.816

I will try my level best to abstain in the next 3 months

Abstinence

Behavioural Beliefs

Abstinence Partner

Reaction

Abstinence Prevention

Beliefs

Abstinence Socio

Cultural Beliefs

Abstinence Normative

Beliefs
If I abstain from sex ... parenthood, I will be proud of 3 myself.

If I abstain from sex ... my parents will be proud of me If I abstain from sex... have the career that I am hoping for

I have been worried that if I talked might lgnore my request

I have been worried that if I talked might threaten to hit me

I have been worried that if I talked might swear at me or call me ugly names

I have been worried that if I talked might threaten to leave me

I have been worried that if I talked might threaten to leave me hit or push or kick me

I have been worried that if I talked might leave me

I have been worried that if I talked might go out with other girls/ boys

Abstinence prevents contracting STDs

2

0.867

If I abstain from sex, I am less likely to get HIV.

If a guy abstains from sex, his penis will not erect 5 anymore.

If a guy abstains from sex for a long time, he will lose his mind

If a girl abstains from sex too long, giving birth will be very difficult

If a person abstains from sex for too long, he or she will die young

If I abstain from sex, it shows I am not grown up

My boyfriend/girlfriend would think it is ok for me to 5 abstain from sex in the next 3 months

My mother/female guardian---------

My father / male guardian------- 


\section{Statistical Analysis}

Frequencies are reported and chi square tests of association are used to test for differences between genders for categorical data. For continuous data, descriptive statistics like mean and standard errors are reported for both males and females. Independent t-tests are used to test for differences among gender groups for continuous variables like age and abstinence intention. Cronbach's alpha statistics are used to test for internal consistency within constructs and only alphas greater than 0.60 were reported. Initial responses adopted a 5 point likert scale; however, constructs were done as according to Table I. We investigated associations between abstinence intention and different beliefs, e.g., behavioural, normative, etc., by fitting separate univariate general estimation equations (GEE) models that incorporated clustering within clinics. We report regression coefficients, 95 per cent confidence intervals and corresponding $\mathrm{p}$-values for both the unadjusted and adjusted models for age and gender.

\section{Results}

Characteristics of Respondents

Among the 98 HIV positive adolescents, 55 (56 \%) were females, mean age was $15.73(\mathrm{SE}=0.19)$, (97 $\%, n=88)$ have attended school and $(3 \%, n=2)$ reported that they lived alone most of the time. Among the $(17 \%, n=15)$ that reported that they have ever had sex, $(64 \%, n=9)$ had it within the last three months. Forty per cent, $n=6$, have been forced to have sex, $(43 \%, n=6)$ have used condom all the time and (44 \%, $n=4)$ have been pregnant. Seventeen per cent, $n=15$, also reported to have ever smoked cigarette and $(26 \%, n=24)$ have used alcohol before. Adolescents exhibited higher intentions to abstain from sex (3.69, $\mathrm{SE}=0.123)$, higher behavioural beliefs $(4.03, \mathrm{SE}=0.1 \mathrm{I})$, partner reaction $(3.26, S E=0.016)$ and prevention beliefs (3.53, $\mathrm{SE}=0.128)$. Low scores for both normative (2.48, SE $=0.133)$ and socio cultural beliefs (I.90, $\mathrm{SE}=0.093)$ were also recorded. Sample characteristics did not vary by sex except that males scored higher than females in partner reaction beliefs (3.60 vs 2.99, $p=0.003$ ) [Table 2].

Table 2: Demographic, behavioural characteristics, abstinence intention and related abstinence beliefs of respondents, by gender. ALWHA (June 2009 and July 20I0)

\begin{tabular}{|c|c|c|c|c|}
\hline & Males $(\mathrm{N}=43)$ & Females $(N=55)$ & P-Value & Total $(\mathbf{N}=98)$ \\
\hline $\mathrm{Age}^{\mathrm{a}}$ & $|5.8|(0.2 \mid 4)$ & $15.66(0.179)$ & 0.5830 & $15.73(0.187)$ \\
\hline Attended to school & $40(97.6)$ & $48(96.0)$ & 0.6780 & $88(96.7)$ \\
\hline Live alone most of the time & None & $2(4.4)$ & 0.2270 & $2(2.6)$ \\
\hline Ever had sex & $7(\mid 7.5)$ & $8(16.0)$ & 0.8500 & $15(16.7)$ \\
\hline Had sex in the last 3 months ${ }^{b}$ & $3(50.0)$ & $6(75.0)$ & 0.3300 & $9(64.3)$ \\
\hline Reported forced sex ${ }^{b}$ & $2(28.6)$ & $4(50.0)$ & 0.3980 & $6(40.0)$ \\
\hline $100 \%$ condom use ${ }^{b}$ & $3(50.0)$ & $3(37.5)$ & 0.6400 & $6(42.9)$ \\
\hline $\begin{array}{l}\text { Ever } \\
\text { pregnant/impregnated been } \\
\text { someone }^{b}\end{array}$ & None & $4(66.7)$ & 0.0580 & $4(44.4)$ \\
\hline Ever smoked cigarette & $4(10.3)$ & $\mathrm{II}(2 \mid .2)$ & 0.1660 & $15(16.5)$ \\
\hline Ever used alcohol & $10(25.0)$ & $14(26.4)$ & 0.8770 & $24(25.8)$ \\
\hline \multicolumn{5}{|l|}{ Dependent Variable } \\
\hline Abstinence Intention ${ }^{\mathrm{a}}$ & $3.64(0.175)$ & $3.73(0.174)$ & 0.7100 & $3.69(0.123)$ \\
\hline \multicolumn{5}{|l|}{ Independent variables } \\
\hline Behavioral Beliefs $^{\mathrm{a}}$ & $3.95(0.162)$ & $4.10(0.166)$ & 0.7670 & $4.03(0.117)$ \\
\hline Normative Beliefs ${ }^{a}$ & $2.62(0.188)$ & $2.37(0.188)$ & 0.3480 & $2.48(0.133)$ \\
\hline
\end{tabular}




$\begin{array}{lllll}\text { Partner Reaction }^{\mathrm{a}} & 3.60(0.134) & 2.99(0.148) & 0.0030 & 3.26(0.106) \\ \text { Prevention Beliefs }^{\mathrm{a}} & 3.64(0.187) & 3.44(0.174) & 0.4400 & 3.53(0.128) \\ \text { Socio Cultural Beliefs }^{\mathrm{a}} & 1.99(0.152) & 1.83(0.115) & 0.1010 & 1.90(0.093)\end{array}$

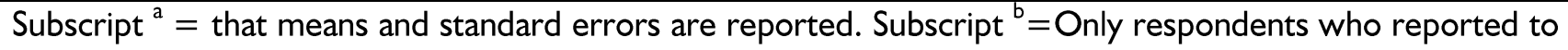
have ever had sex were considered $(n=\mid 5)$.

\section{Correlates of intention to abstain}

Table 3 shows results of the models fitted. All unadjusted models show significant relationships at five percent level of significance except for partner reaction. After adjusting for age and sex, intention to Discussion

The reasoned action approach provided a useful framework to determine the correlates for abstinence intention. The study reveals that most adolescents living with HIV and AIDS had higher intention to abstain from sex. This finding is consistent with findings from (Masters, 2008) who argue that both male and female adolescents reported positive attitudes about abstinence. However males depicted lesser positive attitudes towards abstinence when compared with their female counterparts. These findings corroborate with(Stanton, 1998) who also found that in an abstinence and safer sex sexual practices intervention, females appeared to delay the initiation of sexual activity, while male virgins increase condom use at initiation of sex, I year post intervention. abstain will increase as a result of increasing behavioural and prevention beliefs [0.58, $\mathrm{Cl}$ : $(0.3694$, $0.785)$, and $0.42, \mathrm{Cl}:(0.213,0.620)$ respectively, $\mathrm{p}<0.000$ I for both variables]. Moreover, a normative beliefs increase results in a decrease in abstinence intention [-0.27, $\mathrm{Cl}:(-0.440,-0.03), \mathrm{p}=0.0250]$. adolescents were unwilling to embrace behavioural challenges when compared to adults. Corroborating with these findings,(Ogunjuyigbe, 20I4) recommend the need for improving adolescent health and reducing teenage pregnancy as an important aspect of policy intervention. They further advocate for the need for youth to have healthy transitions so as to contribute to their development. This is an important finding especially in Botswana where HIV and AIDS prevalence is at its highest. The researchers acknowledge that this strategy might delay sexual debut but it is not permanent, as reflected by the few who engaged in sexual activity which for some resulted in pregnancy. The authors support that this strategy be coupled with other interventions to prevent pregnancy, STDs and reinfection as suggested by the literature (Lacson, 1997); (Jemmott,

Table 3: Unadjusted and adjusted coefficients, $95 \%$ confidence intervals, and p-values for Abstinence beliefs on Abstinence Intention ALWHA (June 2009 and July 2010)

\begin{tabular}{lllll}
\hline & \multicolumn{2}{l}{ Unadjusted for Age and Gender } & \multicolumn{2}{l}{ Adjusted for Age and Gender } \\
Covariates & COEFFICIENT $(95 \% \mathrm{CI})$ & P-value & COEFFICIENT $(95 \% \mathrm{CI})$ & P-value \\
\hline Behavioural Beliefs & $0.5920(0.388,0.795)$ & $<0.000$ & $0.5772(0.3694,0.785)$ & $<0.000$ \\
Partner Reaction & $0.2210(-0.038,0.4780)$ & 0.0940 & $0.2246(-0.047,0.496)$ & 0.1000 \\
Prevention Beliefs & $0.4340(0.2400,0.628)$ & $<0.000$ & $0.4164(0.213,0.620)$ & $<0.000$ \\
Socio $\quad$ Cultural & $-0.3060(-0.580,-0.032)$ & 0.0290 & $-0.2663(-0.553,0.020)$ & 0.0680 \\
Beliefs & I & 0.0130 & $-0.2348(-0.440,-0.03)$ & 0.0250 \\
Normative Beliefs & $-0.2550(-0.457,-0.053)$ & & &
\end{tabular}

(Masters, 2008) further elucidate that female participants embraced abstinence as socially desirable. Participants also viewed abstinence as a developmentally appropriate stage, however complex. They also recommend that there is need for them to be empowered with negotiation and decision-making skills geared at abstinence. These findings are consistent with (Adeokun, 2005) who posit that there is need for effective programs to address the special needs of adolescents. In this study
20I0); (Kirby, 20II); (Masters, 2008). The finding that some adolescents were forced into having sex is disturbing because it predisposes them to STDs, unwanted pregnancies and re-infection with other HIV strains.

(Kacaneck, 2016)observed that youth with paediatric HIV and violence exposure in the past year had two-fold elevated odds of having unsuppressed viral load, and recent indirect exposure to violence was associated with CD4\% less than 25\% among 8 to I5 year old participants. Despite the education and 
counselling these adolescents receive at the Children's centre and IDCC they still engaged in risky social behaviours such as smoking and alcohol use which is detrimental to their health. This is consistent with (Weiser, 2006) who argue that there is need for utilisation of different strategies in addressing risky behaviour that can avert HIV infection. These strategies should take into consideration the social, cultural and structural contexts of the country

We observed that both behavioural and prevention beliefs were positively associated with abstinence intention. Corroborating with these findings are (Zhang, 20I5) who argue that abstinence only intentions work through behavioural beliefs regarding the positive consequences, rather than the negative consequences of sex.

However, we also observed a negative association between normative beliefs and abstinence intention. This implies that what significant others of ALWHA think or say about their intention to abstain had little or no bearing on their decision. This is in disagreement with other studies which recognise the role of significant others, especially parents, in influencing sexual intentions and norms of adolescents (Cha, 2007); (Hutchinson, 2007); (Hutchinson, 2012) . Socio- cultural beliefs did not find support among adolescents in this study. This implies that the influence of socio-cultural norms that perpetrate beliefs about risky sexual intentions and behaviours were not substantiated in this study.

Adolescent living with HIV and AIDS were also cognisant of how their partners would react if they vocalised their abstinence intention, a sign of peer pressure as is the case with any other adolescents. It is also noteworthy that these adolescents were highly self - efficacious about abstinence intention, and believe that abstinence will avert the risk of contracting STIs and HIV and AIDS (Chilisa, 20I3). Such kind of attitude will reduce the likelihood of engaging in sex out of peer pressure and also help them resist any negative cultural beliefs that can perpetrate engagement in risky sexual practices.

While abstinence only approaches have an important role in preventing adolescent sexual involvement(Jemmott, 2010) they may not be practical; they need to be augmented by other approaches like provision of appropriate skills and a conducive environment to harness abstinence (Kirby, 20II). This assertion finds substantiation from (Santelli, 2006)who also argue that although abstinence from sexual intercourse represents a healthy behavioural choice for adolescents, policies and programs relying only on such are scientifically and ethically unsound. The argument advanced is that 'abstinence only' interventions often fail to prevent pregnancy and disease. The authors further critique 'abstinence only' programs on the basis that they promote a specific moral viewpoint, not a public health approach. As such they are not in agreement with commonly accepted notions of human rights. A further recommendation is for schools and health care providers to encourage abstinence as an important choice for adolescents. However 'abstinence only' as a basis for health policy and programs should be forsaken (Santelli, 2006);(Masters, 2008).

HIV remains an impediment for investment in the youthful labour force that Botswana is endowed with. High HIV prevalence is especially noted among females than males, and gender differentials exist with regard to safer sex practices. Investing in sexual and reproductive health interventions that are gender sensitive is likely to turn the tide of HIV and AIDS and encourage full participation of both genders in the economy. Targeting beliefs and behaviours that predispose ALWHA to sexual risk will go a long way in averting re- infections and new infections. Ultimately a healthy working age labour force that exists within a conducive socio- cultural and stable political environment will in turn catalyse the reaping of a demographic dividend.

\section{Conclusion}

Behavioural, prevention and normative beliefs successfully predicted intentions to abstain from sex. All these behaviours will increase the ALHWA's intention to abstain. Partner reaction and socio cultural beliefs do not statistically affect the intention to abstain according to the information received from these subjects. The recommendation is that investing in programmes that build behavioural, prevention, and normative beliefs will go a long way in reducing risk of re-infection by increasing the intention to abstain from sex among ALHWA.

\section{Recommendations for Further Research}

The authors recommend the need for designing culturally congruent studies that can take into account the context within which adolescent living with HIV and AIDS exist. Theory driven research can modify risky sexual practices that predisposes adolescent to reinfection and STIs.

\section{Limitation}

Due to the sensitive nature of HIV research, the recruitment of adolescents living with HIV was a challenge. A limitation of this study is that the sample size of 98 is small because there were few adolescents who fell into the age category of 15-19 years at the time of enrolment. Obtaining consent 
and assent from parents and caregivers and assent from adolescents was also tedious and limiting. Another issue was that the resources were limited to allow for recruitment in other sites.

\section{Acknowledgement}

This research was sponsored through NIH GRANT NO. R24HD056693 - 05. The collaborating partners were University of Pennsylvania and the University of Botswana. Our gratitude goes to the adolescents living with HIV and AIDS who selflessly contributed to the study, together with their parents/guardians and the health care providers.

\section{Contribution of Authors}

Author ( $a, b, \&$ c) were involved at the conceptual phase of the paper. Author a) produced a draft of the paper. Authors (a) and (b) then worked on the second draft following input from the team. Author (c) provided guidance throughout writing of the paper and made edits. Author (d) provided the statistical analysis. All authors participated in the finalization of the manuscript.

\section{References}

ADEOKUN, L. A., LADIPO, O.A., KANKI,P., DELANO, G.E., CARRINGTON, A. \& ODIMEGWU, C.O 2005. The role of HIV/AIDS prevention campaigns on HIV - related behavioural changes in Ibadan, Nigeria. African Population Studies, 20, 43 - 63.

AJZEN, I. 199I. The theory of planned behaviour. Organisational Behaviour and Human Decision Processes, 50, I79 - 211 .

AJZEN, I., FISHBEIN,M 1980. Understanding attitudes and predicting social behaviour.

BUSZA, J., BERSANA,G.V.R 20I3. "I have grown up controlling myself a lot". Fear and misconceptions about sex among adolescents vertically - infected with HIV in Tanzania. Reproductive Health Matters, 21, 87 - 96.

CHA, E. S., DOSWELL, W.M., KIM, K.H., CHARRON- PROCHOWNIK, D., \& PATRICK, T.E 2007. Evaluating the theory of planned behaviour to explain intention to engage in premarital sex amongst Korean college students: A questionnaire survey. International Journal of Nursing Studies, 44, I I 47 - I I 57.

CHILISA, R., TLHABANO, K., VISTA, C., PHEKO, M., LOSIKE, N., MOSIME, S., MPETA, K., \& BALOGUN, S.K 20I3. Self - efficacy, self- esteem and intention to practice safe sex among Batswana adolescents. IOSR Journal of Humanities and Social Sciences, 9, 87 - 95.
CULP- RESSLER, T. 2014. The failures of abstinence - only education illustrated in 2 charts.

FISHBEIN, M. A., I 1975. Belief, attitude, intention and behaviour.

FISHBEIN, M. A., I 20I0. "Predicting and changing behaviour:the reasoned action approach".

GEORGES, G., SIMONA,B 2013. "Why are virgin adolescent worried about contracting HIV/AIDS? Evidence from four Sub - Saharan countries". African Journal of Reproductive Health, I7, 32.

GHAFFARI, M., GHARGHANI,Z.G., MEHRABI, Y., RAMENZANKHANI, A., \& MOVAHED, M. 2016. Premarital sexula intercourse - related individual factors among Iranian adolescents: A qualitative study. Iran Red Crescent Medical Journal, 18, e2I 2220 .

GODSWILL, J. 2014. Adolescents' sexual and reproductive health challenges in Northern Nigeria: Roadmap to effective interventions. International Letters of Social and Humanistic Sciences, 24, 11.

HUTCHINSON, M. K., \& WOOD, E.B 2007. Reconceptualizing adolescent sexual risk in a parent-based expansion of the theory of planned behaviour. Journal of Nursing Scholarship, 39, I4I - 146.

HUTCHINSON, M. K., KAHWA, E., WALDRON, N., BROWN, C.H., HAMILTON, P.I., HEWITT, H.H., AIKEN,J., CEDERBAUM, J., ALTER, E., \& JEMMOTT, L.S 2012. Jamaican mothers' influence of adolescent girls' sexual beliefs and behaviours. Journal of Nursing Scholarship, 44, 27 - 35.

JEMMOTT, J. B., 3RD 20I2a. The reasoned action approach in HIV risk-reduction strategies for adolescents. The Annals of the American Academy of Political and Social Science, 640, 150172.

JEMMOTT, J. B. R. 20I2b. The reasoned action approach in HIV risk - reduction strategies for adolescents". The Annals of American Academy of Political and Social Sciences, 640, 150 - 172.

JEMMOTT, J. B. R., JEMMOTT, L.S 20I0. "Efficacy of a theory- based abstinence - only intervention over 24 months: A randomized vontrolled trial with young adolescents". Arch Paediatric Adolescent Medicine, 164, I52 - I59.

KABIRU, C. W. E., A 2007. Factors associated with sexual abstinence among adolescents in four SubSaharan countries. African Journal of Reproductive Health, II, I I - I 32.

KACANECK, D., MALEE, K., MELLINS,C.A., TASSIOPOULOS, K., SMITH, R., GRANT, M., LEE, S., SIDDIQUI, D.Q., \& PUGA, A 2016. Exposure to violence and virologic and immunological outcomes among youth with 
perinatal HIV in the pediatric HIV/AIDS cohort study. Journal of Adolescent Health, 59, 30 - 37.

KASBOM, A. A., SYDSJO, G 2016. Differences in sexual behaviour, health, and history of child abuse among school students who had not engaged in sexual activity by the age of 18 years: a cross- sectional study. Adolescent Health, Medicine and Therapeutics, 7, I - I0.

KIRBY, D., COYLE, K 20II. "Reducing adolescent sexual risk", ATR Associates.

LACSON, R. S., THEOCHARIS, T.R 1997. "Correlates of sexual abstinence among urban University students in the Phillipines". International Family Planning Perspectives, 23, $168-172$.

LEERLOOIJER, J. J., RUITER, R.A.C 2014. "Psychosocial correlates of motivation to abstain from sexual intercourse among Indonesian adolescents". Tropical Medicine and International Heslth, 19, 74 - 82.

MASTERS, N. T., BEADNELL,B.A., MORRISON, D.M. HOPPE, M.J., \& GILLMORE, M.R 2008.

The opposite sex? Adolescents' thoughts about abstinence and sex, and their sexual behaviour". Perspectives on Sexual and Reproductive Health, 40, 87 - 93.

MBALINDA, S. N., KIWANUKA, N., ERICKSON, L.E., WANYENZE,R.K., \& KAYE, D.K 20I5a. Correlates of ever had sex among perinatally infected HIV infected adolescents in Uganda. Reproductive Health I2, 96.

MBALINDA, S. N., KIWANUKA, N., KAYE, D.K., \&ERIKSSON, L.E 20I5b. "Reproductive health and lifesyle factors associated with health - related quality of life among peri - natally HIV - infected adolescents in Uganda". Health and Quality of Life Outcomes, 13, 170.

MERGUI, A. G., A 20II. "The sexuality of HIV infected adolescents: Literature review and thinking on the unthinkable of sexuality". Arch Paediatric 18, 797 - 805.

MHALU, A., LEYNA, G.H 20I3. "Risky behaviours among young people living with HIV attending care and treatment clinics in Dar Es Salaam, Tanzania: Implication for prevention with a positive approach". Journal of International AIDS Society, 16, 17342.

NACA 20I4. Botswana 2013 globaal AIDS response report: Progress report of the national response to the 20II Declaration on Commitments on HIV and

AIDS

http://www.unaids.org/site/default/files/en/dataana lysis/knowyourresponse/countryprogressreports/2 0I4countries/BWA narrative report 20I4.pdf.
NJAU, B., MTWEVE, S 2009. Gender differences in intetion to remain a virgin until marriage among school pupils in rural Northern Tanzania. African Journal of AIDS Resesrach, 8, 157 - 166.

OGUNJUYIGBE, P. O., ADEPOJU,A 2014. Perspectives on socio - cultural context of adolescent reproductive health behaviour in Nigeria. African Population Studies, 27, 343.

OLADEPO, O. F., M.M 20II. Perceptions about sexual abstinence and knowledge of HIV/AIDS prevention among in- school adolescents in a western Nigerian city. BMC Public Health, II, 304.

RIJSDIJ, K. L., BOS, A.E.R, LIE, R. 20I2. Correlates of delayed sexual intercourse and condom use among adolescents in Uganda. BMC Public Health, 12,817 .

SACOLO, H. N., CHUNG, M., CHU, H., LIAO, Y., CHEN, C., OU, K., CHANG, L., \& CHOU, $\mathrm{K}$ 20I3. High risk sexual behaviours for HIV among the in- school youth in Swaziland: Astructural equation modelling approach. PLOS ONE, 8, e67289.

SANTELLI, J. O., M.A, LYON, M., ROGERS, J. 2006. "Abstinence and abstinence - only education: A review of U.S policies". Journal of Adolescent Health, 38, 72 - 8I.

STANTON, B. F., LI, X., KAHIHUATA, J., FITZGERALD, A.M., SIMEONE, N., KANDUUOMBE, G., RICARDO, I.B., GALBRAITH, J.S., TERRERI, N., GUEVARA, I., SHIPENA, H., STRIJDOM, J., CLEMENS, R., \& ZIMBA, R.F 1998. Increased protected sex and abstinence among Namibian youth following a HIV risk - reduction intervention: a randomized, longitudinal study. AIDS, I2, 2473 - 2480.

WEISER, S. D., LEITER,K., MACFARLAND,W., PERCY - DE - KORTE, F., DEMONNER,S.M., TLOU,S., PHALADZE, N., IACOPINO, V., \& BANGSBERG, D.R 2006. A population - based study on alcohol and high- risk sexual behaviour in Botswana. Plos Medicine, 3, e392.

ZHANG, J., JEMMOTT, J.B \& JEMMOTT,L.S 2015. Mediation and moderation of an efficacious theory - based abstinence - only intervention for African American adolescents. Health Psychology, 34, I 10. 